\title{
Teknolojik yeniliklerin pencere sistemleri ve üretimi üzerindeki etkilerine yönelik bir araştırma
}

\author{
Tuncer Dilik* (D)
}

$\ddot{\mathbf{O} z}$

Teknolojik yenilikler çerçevesinde geliştirilen ahşap ve diğer malzemelerle kombine edilerek üretilen pencerelerin avantajları sıralanırken, emsallerine göre gerek üretici açısından gerekse kullanıcı açısından ahşabın üstün özelliklerinden ne kadarının sağlandığı veya sakıncalarının ne kadarının giderildiği bir üstünlük olarak vurgulanmaktadır. Günümüzde, bu amaçla geliştirilmiş olan ve üzerinde çalışılan birçok pencere türü ve sisteminin belirlendiği bu çalışmada, sadece ülkemizde patent ve marka hakkını tescil ettirmiş olan kompozit pencere sistemlerinin bazıları hakkında bilgiler verilmektedir. Çalışmada, örnek pencere sisteminin hava geçirgenliği sınıfı A3, su geçirgenliği (sızdırmazlık) sınıfı ise RA7 olarak belirlenmiştir. $\mathrm{Bu}$ sonuçlara göre, ilgili standart değerlerde belirtilen en yüksek kalite ve performans sinıfının A4 ve RA9 olduğu göz önüne alınacak olursa woodcom pencerelerin oldukça yüksek performans kalitesini sağladığ 1 görülmektedir. Kompozit pencere sistemlerinin, pencere sektöründe en son geliştirilen sistemler olarak, farklı model ve tasarımlarla ahşabın diğer malzemelere olan üstün özellikleri ile PVC veya alüminyumun dayanıklılığını, montaj ve kullanım kolaylığını kombine eden avantajlarıyla pencere pazarında bulundukları ve pazar paylarını arttırmakta oldukları görülmektedir.

Anahtar kelimeler: Pencere sektörü, pencere teknolojisi, pencerelerin görevleri

\section{A research on the effects of technological innovations on window systems and production}

\begin{abstract}
As stating advantages of these composite window profile systems producing by developing technological innovations on the other hand to which extend obtained superior characteristics and eliminated disadvantages of wood material thinking as manufacturers and customers point of view compared to other materials used were emphasized. Many window profiles which were developed according to technological innovations in Turkey and on which dealers still have been studying; also, application areas were determined in this study. In the research, it was found that the air permeability class of the sample window systems was A3 and the water tightness class was RA7. According to these results, considering that the highest quality and performance class specified in the relevant standard values are A4 and RA9, it is seen that woodcom windows provide very high-performance quality. Finally, knowledge about some composite window profile systems which registered their patent right and brand in Turkey were presented. Lastly developed composite window profile systems with various types and designs which undertake superior characteristics of wood material compared to PVC and aluminium in the point of view such as superior strength properties, assembling and usage easiness were determined to take part and increase their demand ratio in window market.
\end{abstract}

Keywords: Window sector, window technology, functions of windows.

Makale tarihçesi: Geliș: 05.06.20, Kabul: 20.06.2020, Yayınlanma: 29.06.2020, *e-posta: tuncerd@ istanbul.edu.tr *İstanbul Üniversitesi-Cerrahpașa Orman Fakültesi, Orman Endüstri Mühendisliği Bölümü, İstanbul/Türkiye 


\section{Giriş}

Teknolojik gelişmelere paralel olarak dünyada pencerelerin üretimi, miktarı ve nitelikleri, özellikle gelişen mimari kavramlar ve inşaat teknikleri, ekonomik, sosyal-kültürel değerler ve ekolojik yaklaşımlar nedeniyle değişmektedir. Bu değişimlere örnek olarak, pencere üretiminin geleneksel ve vazgeçilmez malzemesi olan ahşap malzemenin kullanımının, alternatif malzemelere (plastik, alüminyum ve kompozit malzemelere) karşı kaybetmiş olduğu üstünlüğünü teknolojik yenilikler sayesinde geliştirilen pencere sistemleri ile yeniden kazanmaya başlaması gösterilebilir. Zira, akıllı ahşap teknolojileri kapsamında geliştirilen tasarımlar ile kompozit (PVC+Ahşap, Alüminyum+Ahşap, PVC+Alüminyum+Ahşap) malzemelerden üretilen pencerelerin avantajları sıralanırken emsallerine göre gerek üretici açısından, gerekse kullanıcı açısından ahşabın üstün özelliklerinden ne kadarının sağlandığını veya sakıncalarının ne kadar giderildiği bir ayrıcalık olarak vurgulanmaktadır (Şekil 1) (Dilik ve Kurtoğlu, 2019; URL 1, 2020).

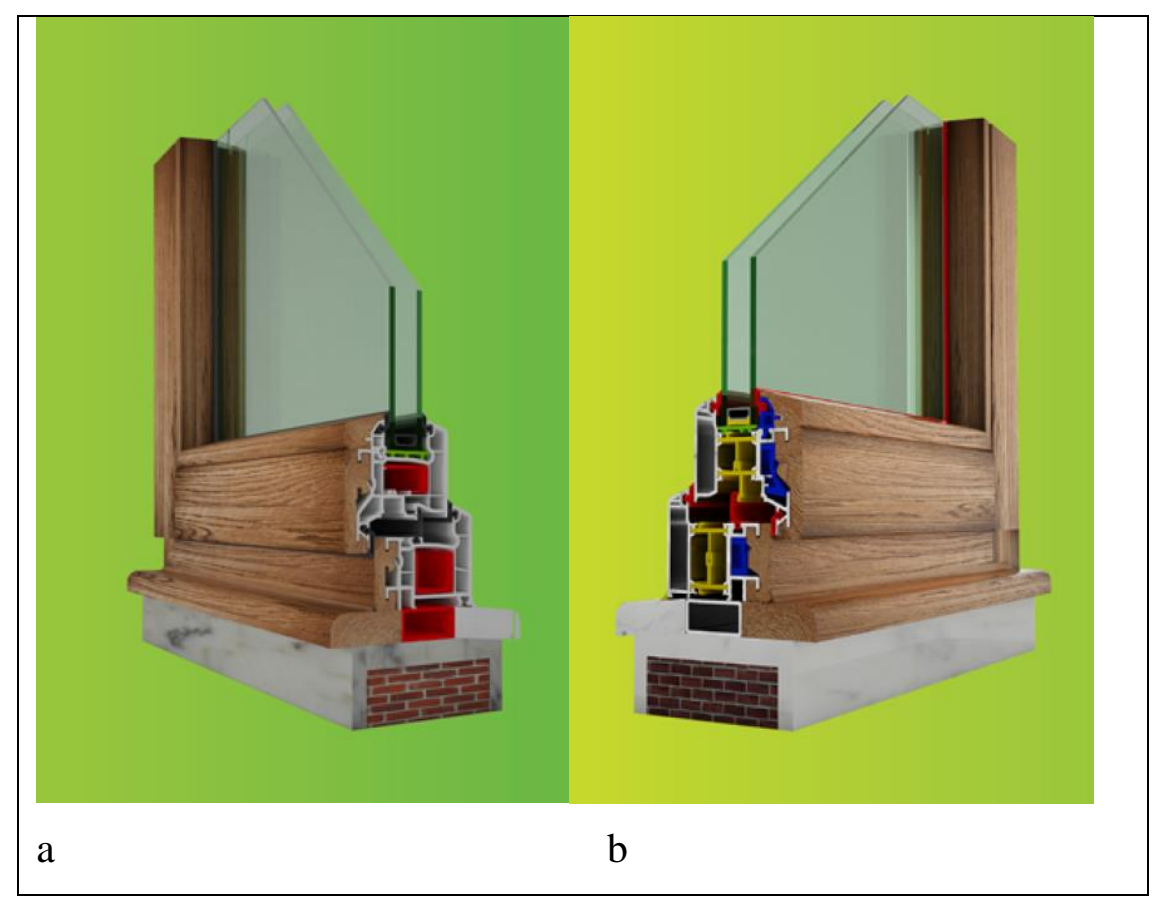

Şekil 1. Smart Wood Technology patentli tasarım örnekleri; a- PVC ahşap pencere sistemi, bAlüminyum ahşap pencere sistemi (URL 1, 2020).

Günümüzde malzeme tercihlerinde olduğu gibi çeşitli faktörlerin (ekonomik, teknolojik ve ekolojik yaklaşımlar vb.) pencerelerden olan beklentileri etkilediği görülmektedir. Son zamanlarda, pencereler üzerindeki bu faktörlere yönelik literatür ve araştırma-geliştirme çalışmalarının yoğunluğu bu durumu açıklamaktadır (Dilik ve Kurtoğlu, 2019). Bu çerçevede, pencerelerden olan beklentilerin ve pencere üretimindeki gelişimin aşağıda belirtilen özelliklere sahip olduğu görülmektedir. Bunlar;

1. Günümüzün yükselen yaşam standartları çerçevesinde, ortak yaşam alanlarının şekillenmesinde, insanlara daha kaliteli ve farklı tercihleri seçme olanağı tanımalıdır.

2. Yapılardaki hava, 1şık, ses, görsel ilişki ve dış mekanlar ile bağlantıyı sağlama işlevleri gibi temel görevlerini yerine getirirken, konfor sağlamanın dışında yalıtım, güvenlik ve denetim gibi birçok hayati ihtiyacı da birlikte yerine getirmelidir. 
3. Pencerelerin görevleri ile ilgili olarak belirtilen fonksiyonları yerine getirirken sıcağa ve soğuğa, aşırı güneş 1şınlarına karşı koruma sağlama, ses iletimini azaltma, estetik olma, kolayca temizlik ve bakım yapılabilmesi ve ekonomik olması gibi önemli özelliklerinin belirlenmesi gerekmektedir.

4. Günümüzde kullanılan bütün malzemeler çevre sağlığına etkilerinin olumlu veya olumsuz olması ile değerlendirilmektedir. Bu nedenle, üretilen ve kullanıma sunulan pencerelerin de ekolojik profile uygun ve geri dönüşümlü bir malzemeden üretilmiş olmas1 gerekmektedir.

$\mathrm{Bu}$ gerekçelerle, pencerelerin tasarımında, malzeme seçiminde ve üretiminde kullanım amaçlarına uygun özelliklerin dikkate alınması gerekmektedir. Ahşap pencerelerin bu özellikleri ile ilgili olarak, tarihi binalarda bakımsızlıklarına rağmen uzun yıllar sağlam kalması ve hala işlevlerini yerine getirebiliyor olmaları, tasarımı, malzeme seçimi ve bakımının doğru yapıldığı takdirde ahşap malzemeden üretilen pencerelerin uzun süre dayanıklılığını koruyabileceğine ilişkin en güzel göstergedir. Buna karşın, orman varlığının azalması ve pahalılaşması, ağaç malzemenin önemini daha da arttırarak rasyonel kullanımı zorunlu k1lmaktadir.

$\mathrm{Bu}$ çalışmanın amacı, teknolojik yeniliklerin pencere sistemleri ve üretimi üzerindeki etkilerinin ortaya çıkarılması olup, tüm endüstriyel üretimlerde olduğu gibi pencere üretiminde de kullanılan bütün malzemelerin yararlı ve sakıncalı yönlerini gözeten ve kombine eden tasarımların araştırılmasıdır. Bu bağlamda geliştirilmiş olan, woodcom pencere sistemlerinin hava geçirgenliği ve su geçirgenliği (sızdırmazlık) testleri üzerinden kalite ve performans denemeleri yapılarak değerlendirmelerde bulunulmuştur.

\section{Materyal ve Metot}

$\mathrm{Bu}$ araştırmada, teknolojik yenilikler çerçevesinde, pencere üretiminde kullanılan malzemelerin günümüzdeki tercih durumları ile bu tercihler üzerindeki etkileri sonucu geliştirilmiş olan pencere sistemleri incelenmiştir. Bu amaçla, geliştirilmiş olan pencere sistemlerine yönelik olarak literatür taraması ile bu alanda patentli bir tasarım olan woodcom pencere sistemi araştırılmıştır.

Araştırmada, woodcom pencereler üzerinde kalite ve performans denemeleri olarak sadece hava geçirgenliği ve su geçirgenliği (sızdırmazlık) testleri, 100x100 cm boyutlarına sahip açlır tek kanatlı bir pencere numunesi üzerinde yapılmıştır. Bu denemeler, TS EN 1026, 2002; TS EN 1027, 2003 standartlarına göre uygulanmıştır.

$\mathrm{Bu}$ kapsamda, elde edilen verilere göre woodcom sisteminin pencerelerden olan beklentileri karşılama durumu belirlenmeye çalış1larak, pencere sektörüne yönelik bir genel bir değerlendirme yapılmıştır.

\section{Bulgular ve Tartışma}

\subsection{Pencere üretiminde malzeme tercihleri}

Doğrama ve özellikle pencere üretiminde ilk kullanılan malzeme ahşaptır. Daha sonra sanayinin gelişmesine paralel olarak demir, alüminyum, PVC ve kompozit malzemeler doğrama üretiminde kullanılmaya başlanmıştır. Özellikle ahşap, PVC ve alüminyum pencere üretiminde kullanılan malzemelerin tamamına yakın kısmını (\% 95) oluşturmaktadır. Aşağıda pencere üretiminde kullanılan malzemelere ait önemli teknik özellikler karşılaştırma amacıyla verilmiştir (Çizelge 1). 
Çizelge 1. Pencere üretiminde kullanılan malzemelerin karşılaştırılması (Işık, 1994).

\begin{tabular}{|l|c|c|c|}
\hline \multicolumn{1}{|c|}{ Teknik özellikler } & Ahşap & Plastik (PVC) & $\begin{array}{c}\text { Metal } \\
\text { (Alüminyum Alaşımları) }\end{array}$ \\
\hline Isı geçiş katsayısı $(\lambda)$ & $0.14 \mathrm{~W} / \mathrm{mK}$ & $0.16 \mathrm{~W} / \mathrm{mK}$ & $201 \mathrm{~W} / \mathrm{Mk}$ \\
\hline Genleşme katsayısı(K-1) & $4 \times 10-6$ & $80 \times 10-6$ & $22 \times 10-6$ \\
\hline Elastikiyet modülü & $11000 \mathrm{~N} / \mathrm{mm}^{2}$ & $2600 \mathrm{~N} / \mathrm{mm}^{2}$ & $70000 \mathrm{~N} / \mathrm{mm}^{2}$ \\
\hline Eğilme direnci & $50-130 \mathrm{~N} / \mathrm{mm}^{2}$ & $60-80 \mathrm{~N} / \mathrm{mm}^{2}$ & $150-300 \mathrm{~N} / \mathrm{mm}^{2}$ \\
\hline
\end{tabular}

Ahşap malzeme, hammadde ve malzeme olarak teknolojik, fiziksel ve mekanik bakımdan sahip olduğu üstün özellikleri, daha da önemlisi yenilenebilir bir kaynak olması nedeniyle, uzun yıllardan beri vazgeçilmeyen bir malzeme olarak pencere üretiminde kullanılmaktadır. Ancak, son yıllarda pencere üretiminde ahşabın kullanımı, giderek azalan orman kaynakları ve artan ekonomik sorunlarla beraber, kalite ve performans özelliklerindeki olumsuzluklar sonucu önemi ve kullanımı, PVC ve alüminyum alaşımlarına karşılık giderek azalmıştır.

Dünyadaki gelişmelere paralel olarak, nitelikleri sürekli değişmekte olan pencerelerin ve pencerelerden olan beklentilerin bugün, özellikle gelişen mimari kavramlar ve inşaat teknikleri, değișen ekonomik, sosyal-kültürel değerler ve ekolojik yaklaşımlar nedeniyle malzeme tercihlerinin değişmekte olduğu görülmektedir. $\mathrm{Bu}$ yaklaşımlar çerçevesinde pencere sektörünün, dünyada olduğu gibi ülkemizde de modern üretim tekniğini kullanan ve toplam kalite anlayışı içerisinde endüstriyel üretim yapan bir sektör haline geldiği görülmektedir. Bu gelişmeler, özellikle plastik ve alüminyum malzemeden pencere üretiminde gerek üretim miktarı, gerekse dış ticaret hacmi bakımından bariz bir şekilde kendini gösterirken, ahşap pencere üretiminde de hala atölyelerde geleneksel yöntemlerle üretim yapan sektör konumundan çıkmış endüstriyel üretim yapan bir sektör haline gelme çabası içinde büyük atılımlar yaptığı görülmektedir. Pencere sektöründeki bu gelişme ve atılımın ülkemiz açısından da geçerli olduğunu, Türkiye İstatistik Kurumunun verilerine göre Türkiye ahşap, plastik ve metal doğrama endüstrisinin üretim ve diş ticaret değerlerine bakarak söylemek mümkündür (Dilik ve Kuşçuoğlu, 2008).

Diğer taraftan, literatür araştırmalarına dayanarak bu malzemelerin sektörel araştırmalar çerçevesinde belirlenmiş olan tercih durumlarına dayanak olması açısından doğrama ürünleri için belirli bölgelerdeki pazar paylarının gelişimi incelendiğinde; gelişmiş Avrupa ülkelerinde, PVC'nin 1990'lı y1llarda (\%45-52) olan oranı, son y1llardaki teknolojik gelişmeler ve ekolojik yaklaşımlar nedeniyle 2000'li yıllarda (\%37-38), ahşabın1990'lı yıllarda (\%32-38) olan oranı 2000'li yıllarda (\%33-36), alüminyumun ise 1990'l1 yıllarda (\%20-22) olan oran1 2000'li y1llarda (\%19-20), kompozit olarak (ahşap + alüminyum) 1990'larda \%3.5-4 iken 2000'li y1llarda \%6,5-7 de olduğu görülmektedir. Bu duruma göre, PVC'nin ve alüminyum malzeme tercihinin yavaşladığı, ahşap ve kompozit malzemelerin tercihinin ise artış trendinde olduğunu söylemek mümkündür. (Anonim, 1998; Sakarya, 2003; Anonim, 2005; Dilik ve Kuşçuoğlu, 2008; Dilik ve Kurtoğlu 2019).

Ancak, burada pencere üretimindeki malzeme tercihinde ve pazar payında ülkelerin bölgesel konumlarının etkili faktörlerden biri olduğu söylenebilir. Örneğin, İskandinav ülkelerinde alüminyum giydirmeli ahşap pencere kullanımının \%72 gibi oldukça yüksek bir oranda olduğu belirtilmektedir. Buna karşın Japonya' da ise pencere pazarının \%95' ini alüminyum alaşımlarının oluşturduğu görülmektedir (Dilik ve Kurtoğlu, 1998). 


\subsection{Teknolojik yenilikler çerçevesinde üretilen pencere sistemleri}

Günümüzde pencere üretimindeki malzeme tercihleri ve pencerelerden olan beklentiler giriş bölümünde belirtildiği gibi teknolojik gelişmişliğin göstergesi olarak tüm endüstriyel üretimlerde etkilidir. Bu kapsamda, pencere üretiminde de kullanılan bütün malzemelerin yararlı ve sakıncalı yönlerini gözeten ve bunları kombine eden tasarımlarla çalışmanın önemi ortaya çıkmaktadır (Dilik, 1999).

Pencerelerde oluşan 1sı kayıplarının önüne geçmek, bir nevi pencere mühendisliği gerektirmektedir. Doğru seri, doğru cam, evin konumu ve coğrafi konum gibi faktörler, \%80' lere kadar pencereden kaçan 1sı kayıplarının önüne geçebilir. Büyük oranda dışa bağımlı olduğumuz enerji kaynaklarının verimli kullanılarak ülke ekonomisine pozitif katkı sağlanması amacıyla, pencere üreticilerinin termal kamera sistemlerini kullanan PENESKOP uygulamasını başlatmış oldukları görülmektedir. Bu sayede, alüminyum, ahşap ve değiştirme zamanı gelmiş PVC pencerelerdeki 1sı kayıplarını termal kameralar ile ölçerek ihtiyaca uygun çözümler sunulabilmektedir. Özellikle değiştirme pazarında yaşanabilecek 1sı kayıplarını minimuma indirmek, olumsuz müşteri geri bildirim oranlarını düşürmek ve marka değerini korumak için sektörde ilk defa sertifikalı montaj eğitimlerinin yapılmakta olduğu görülmektedir (URL 2).

Son zamanlarda, bu çerçevede tasarlanan ve üretilen pencere türlerinin kompozit sistemler şeklinde üretildiği ve özel isimlerle (Nirvana, RAU-FIPRO X, Woodcom, Alkosan, Aluwood vb. gibi) piyasaya sunulduğu görülmektedir. Ülkemizde akıllı ahşap teknolojileri kapsamında geliştirilen ve üretilmekte olan bu pencere sistemlerinden bazılarını aşağıdaki gibi kısaca açıklayabiliriz.

Nirvana Premium pencere sistemi, üstün enerji verimliliği ile eşsiz 1sı, ses, toz, hava ve su yalıtımı sayesinde yaşam alanlarınız nefes alsın, dünyanın karmaşası evinizin dışında kalsın sloganıyla tasarlanmış patentli bir PVC pencere sistemi tasarımıdır (URL 3).

RAU-FIPRO X pencere sistemi, fiber takviyeli kompozit malzemenin pencerelerde ilk kez kullanıldığı PVC ve cam elyafından üretilen yüksek performanslı bir malzemeye sahip tasarımdir (URL 4).

Aluwood Pencere Sistemi, dış tarafında alüminyum iç tarafında masif ahşap profil bulunan kompozit bir tasarım ürünüdür. Dış taraftaki alüminyum profiller izolasyonlu ve izolasyonsuz olarak konstrükte edilebildiği gibi iç kısımda da geniş kapsamlı ahşap kaplama seçeneklerini kullanma olanağı veren dolayısıyla ahşabın doğallığı ile alüminyumun dayanıklılığı ve sağlamlığını bir araya getiren teknolojik ve ekolojik bir üründür.

Alkosan Pencere Sistemi, ahşap geçmeli alüminyum pencere sistemi olarak geliştirilmiş olan bu pencerelerde ahşabın doğallığı ile alüminyumun dayanıklılığı ve sağlamlığını kombine eden teknolojik ve ekolojik bir üründür.

Alüminyum-Ahşap kombineli bir kompozit tasarımı olarak belirtilen her iki pencere sistemi arasındaki en önemli fark, alüminyum üzerine ahşap kaplamanın yani bağlantı konstrüksiyonudur. Aluwood'da bağlantı özel klipslerle ve adaptörlerle sağlanırken, Alkosan'da ahşabın alüminyumun üzerine iki kanal vasıtası ile geçtiği ve dış hava koşullarına dayanıklı özel reçineli yapıştırıcılar ile preslenerek tutturulduğu görülmektedir.

Woodcom Pencere Sistemi, pencere sektöründe en son geliştirilen bir sistem olarak, ahşabın diğer malzemelere olan üstün özellikleri ile PVC'nin dayanıklılığını, montaj ve kullanım kolaylığını kombine eden teknolojik, ekolojik ve ekonomik özelliklere sahip patentli bir pencere sistemidir (Şekil 2). 


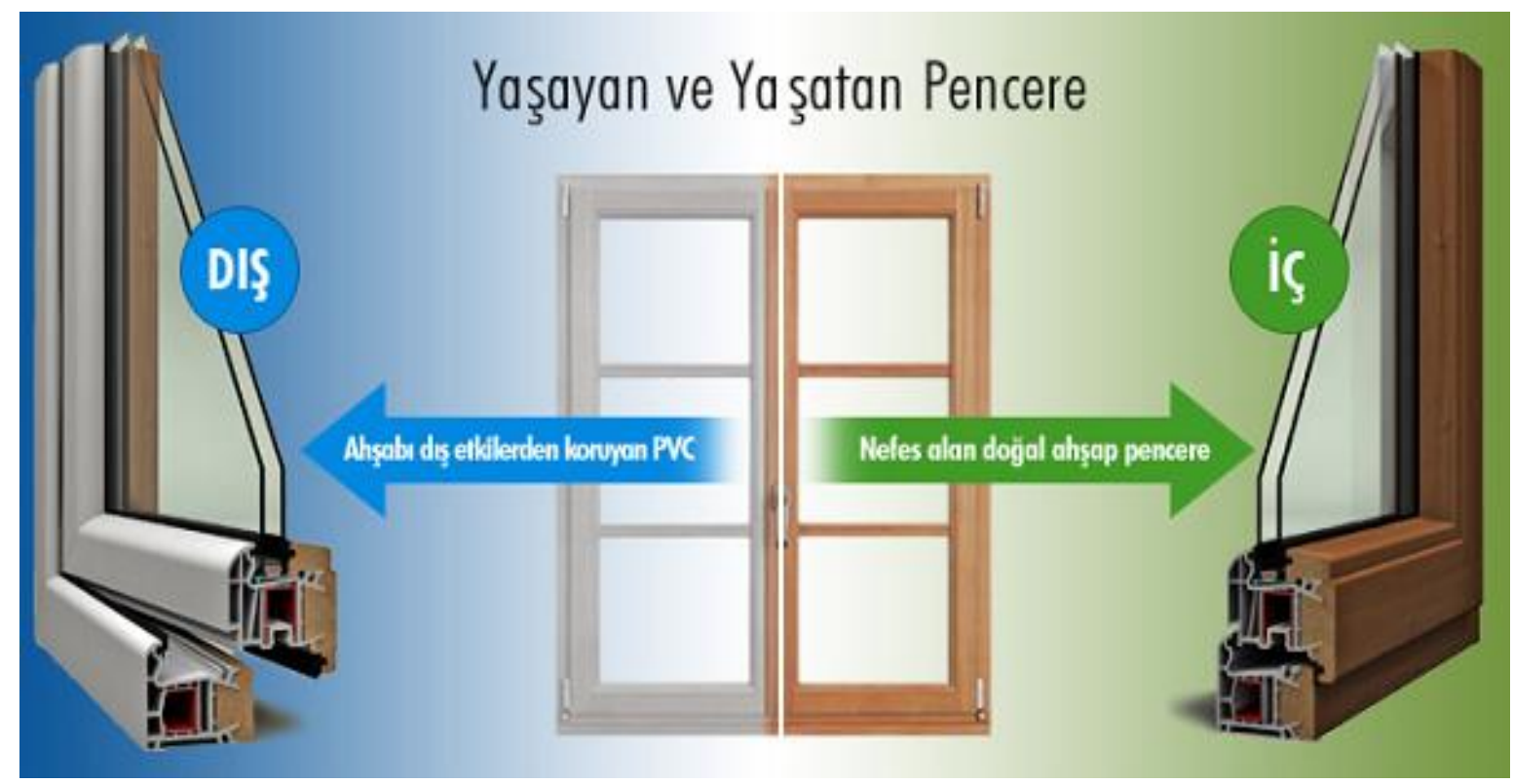

Şekil 2.Woodcom ismiyle geliştirilmiş pencere sistemi örneği (AG Holzmann, 2009)

\subsection{Teknolojik bir pencere sistemi örneği üzerinde incelemeler}

Pencerelerden beklentiler çerçevesinde, teknolojik, ekonomik ve ekolojik gelişmelere paralel olarak geliştirilmiş olan ve üzerinde çalışılan birçok pencere türü ve sistemlerinin bulunduğu 3.2 başlığı altında belirtilmiş ve açıklanmaya çalışılmıştır. Bu çalışmada, sadece deneme olanağı bulunmuş olan woodcom pencere sistemleri üzerinde yapılan inceleme ve test sonuçlarının değerlendirilmesi yapılmıştır.

Araştırmada, woodcom pencerelerde kalite ve performans testlerinden sadece hava geçirgenliği ve su geçirgenliği (sızdırmazlık) testleri yapılmış olup, bu denemelerle elde edilen ilgili standart değerleri Çizelge 2 ve Çizelge 3'de verilmektedir.

Çizelge 2. Hava geçirgenliği testi için belirlenmiş pencere sınıfları ve olması gereken hava kaçakları (TS EN 1026:2002).

\begin{tabular}{|c|c|c|c|}
\hline $\begin{array}{c}\text { Pencere } \\
\text { sınıfı }\end{array}$ & $\begin{array}{c}\text { Verilen en büyük } \\
\text { basınç (Pa) }\end{array}$ & $\begin{array}{c}\text { Pencere birim } \\
\text { alanındaki kaçak } \\
\left(\mathbf{m}^{\mathbf{3}} \mathbf{h}\right)\end{array}$ & $\begin{array}{c}\text { Kullanılan conta birim } \\
\text { uzunluğundaki kaçak } \\
\left(\mathbf{m}^{\mathbf{3}} \mathbf{h}\right)\end{array}$ \\
\hline A0 & 100 & $\mathrm{x}>50$ & $\mathrm{x}>12,5$ \\
\hline A1 & 100 & $25<\mathrm{x}<50$ & $6<\mathrm{x}<12,5$ \\
\hline A2 & 300 & $18<\mathrm{x}<67$ & $4<\mathrm{x}<14$ \\
\hline A3 & 600 & $10<\mathrm{x}<30$ & $2,5<\mathrm{x}<7,5$ \\
\hline A4 & 600 & $\mathrm{x}<10$ & $\mathrm{x}<2,5$ \\
\hline
\end{tabular}

Araştırma çerçevesinde yapılan denemelerde, örnek pencerenin hava geçirgenliği sınıfının A3, su geçirgenliği (sızdırmazlık) sınıfının ise RA7 olarak belirlenmiştir. Bu sonuçlara göre, Çizelge 2'de görüleceği gibi ilgili standartta belirtilen en yüksek kalite ve performans sınıfı olarak hava geçirgenliği sınıfının A4 olduğu, su geçirgenliği sınıfının ise Çizelge 3'de görüleceği gibi RA9 olduğu göz önüne alınacak olursa, woodcom pencerelerin oldukça yüksek 
performans kalitesine sahip olduğu görülmektedir. Diğer taraftan, bu sonuçların masif ahşap ve PVC'den üretilmiş pencereler üzerine yapılmış olan farklı bir araştırma sonuçlarıyla kıyaslaması yapılacak olursa, masif ahşap pencerelerden daha yüksek, PVC'den daha düşük performans kalitesini sağladığı görülmektedir. Zira, adı geçen araştırmada hava geçirgenliği sınıfı, masif ahşap pencerelerde A1 ve A3, PVC pencerelerde ise A4 olarak belirtilirken, su geçirgenliği sınıfı, masif ahşap pencerelerde RA3 ve RA6 olarak, PVC pencerelerde ise RA9 olarak belirtilmiştir (Dilik ve Altun, 2007).

Çizelge 3. Su geçirgenliği testi için belirlenmiş pencere sınıfları (TS EN 1027:2003).

\begin{tabular}{|c|c|c|}
\hline Pencere & \multicolumn{2}{|c|}{ Basınç miktarına göre su kaçakları } \\
\hline RA0 & Basınç yokken & Su kaçağı var \\
\hline RA1 & Basınç yokken kaçak yok & 50 Pa'da su kaçağ1 var \\
\hline RA2 & 50 Pa'da su kaçağ1 yok & 100 Pa'da su kaçağ1 var \\
\hline RA3 & 100 Pa'da su kaçağı yok & 150 Pa'da su kaçağ 1 var \\
\hline RA4 & 150 Pa'da su kaçağı yok & 200 Pa'da su kaçağ 1 var \\
\hline RA5 & 200 Pa'da su kaçağı yok & 250 Pa'da su kaçağı var \\
\hline RA6 & 250 Pa'da su kaçağı yok & 300 Pa'da su kaçağ1 var \\
\hline RA7 & 300 Pa'da su kaçağı yok & 450 Pa'da su kaçağ1 var \\
\hline RA8 & 450 Pa'da su kaçağı yok & 600 Pa'da su kaçağ1 var \\
\hline RA9 & $600 \mathrm{~Pa}$ da & Su kaçağ1 yok \\
\hline
\end{tabular}

Ahşap ve PVC kombineli bir kompozit tasarımı olarak üretilmiş olan bu pencere sisteminin belirlenen avantajlarını aşağıdaki gibi sıralamak mümkündür (Dilik ve Ark., 2009).

1. Woodcom pencereler, normal masif ahşap pencerelere göre hacmen $\% 58$ daha az masif ahşap kullanarak malzemenin tasarruflu ve rasyonel kullanımını sağlamaktadır. Böylece, masif ağaç malzemenin en çok kullanıldığı alan olarak bilinen ahşap pencere üretimindeki sarfiyatı dünya ölçeğinde göz önüne alındığında ağaç malzeme tüketimine ve rasyonel kullanımına önemli miktarda olumlu bir katkıda bulunacağı görülmektedir.

2. PVC ve ahşap kombineli malzeme özelliği ile dış hava koşullarına karşı olan direnci sayesinde mantar, böcek vb. biyolojik zararlılara karşı olan dayanıklılığının da oldukça yüksek olabileceği söylenebilir. Zira, ahşap kısım dış hava koşullarına açık değildir ve iç kısımda PVC üzerine geçme kaplamalı olarak bulunmaktadır. $\mathrm{Bu}$ nedenle, emsallerine göre daha da uzun kullanım ömürlerine sahip olacağı ön görülebilir.

3. Kendine özgü tasarım özellikleri nedeniyle sahip oldukları hava kanalları sayesinde mekandaki havalandırma görevini doğal olarak yerine getirmekte olup, günümüzde pencerelerden olan beklentilerin en önemlilerinden birisi olarak sağlıklı ortamların oluşturulması özelliğine katkıda bulunabilmektedir.

4. Masif ahşap kombineli plastik teknolojisiyle birleştirilmiş özel malzemeden yapılmış olması nedeniyle fırtınaya, darbelere vb. mekanik etkilere karşı olan direnci oldukça yükselebilmektedir. 
5. Bütün kompozit ürünler için sorunlu ve riskli bölge olarak görülen birleşme noktalarındaki rijitliğin sağlanması hususu, woodcom pencerelerde, profil kesitlerinde de görüleceği üzere serbest hareket teknolojisi sayesinde genleşme katsayısı farklı olan plastik ve ahşabın birleşim noktalarındaki zıt yönlü uzantıları içeren özel bir konstrüksiyon ile çözüme kavuşturulmuştur.

6. $\mathrm{Bu}$ sistemin gerek dış cephede gerekse iç cephede sağlamış olduğu normal yalıtım değerlerine (1s1, ses, toz, hava ve su yalıtımı) hacmen \%65 PVC ve \%35 masif ahşap oranı ile ulaşmış bulunduğu görülmektedir. Ahşap sayesinde ortamda elektrostatik bir etkileşim içinde olmadığından plastik pencere gibi toz çekmemektedir.

7. Her türlü mekanizma ve aksesuar kullanımına uygun konstrüksiyon özellikleri sayesinde, yüksek 1S1, ses, toz, hava ve su yalıtımı ile kolay temizlik ve bakımı sağlayarak kullanıcılarına konforu ve tasarrufu beraberinde sunabileceği görülmektedir.

8. Ayrıca, araştırma verilerine ve literatür bilgilerine dayanarak, woodcom teknolojisiyle üretilmiş pencere maliyetinin, aynı boyutlardaki PVC' ye göre birkaç kat daha yüksek olduğu belirlenirken, masif ahşap ve alüminyum pencereye göre daha düşük ve ekonomik olduğu görülmektedir.

\section{Sonuçlar ve Öneriler}

Bu çalışmada, teknolojik pencere sistemleri olarak woodcom pencere sistemi özelinde yapılan inceleme ve bulgular doğrultusunda aşağıdaki sonuçlara ulaşılmıştır.

- Teknolojik yenilikler kapsamında üretilen pencere sistemlerinin, kalite ve performans testlerinden hava geçirgenliği ve su geçirgenliği (sızdırmazlık) denemelerinde A3 ve RA7 olarak oldukça yüksek performans kalitesine sahip oldukları görülmektedir.

- Pencere üretim sektörü için woodcom pencere sisteminin, ahşabın diğer malzemelere olan üstün özellikleri ile PVC'nin dayanıklılığını, montaj ve kullanım kolaylığını kombine eden, teknolojik ve ekonomik özelliklere sahip olma amacıyla tasarlanmış olduğu görülmektedir. Ancak, ekonomik özellikleri ile ilgili boyutu, bu çalışma çerçevesinde araştırılmamış olup, ekonomik özellikleri ile ilgili avantajları, sadece üretici işletme bilgileri ile sınırlı kalmıştır.

- Pencereler için geleneksel üretim malzemesi olan ahşap malzemenin pencere üretimindeki alternatif malzemelere (PVC ve alüminyum) karşı kaybetmiş olduğu üstünlüğünü, teknolojik yenilikler çerçevesinde geliştirilen sistemler ile yeniden kazanmasının olası olduğu ortaya çıkmıştır. Çünkü, pencerelerden olan beklentileri karşılayacak şekilde, sağlıklı, güvenli, estetik ve ekonomik bir pencere üretmek amaciyla tasarlanmış kompozit pencere sistemlerinin hemen hepsinde ahşabın üstünlük ve avantajlarının vurgulandığı ve ileri sürülmekte olduğu görülmektedir.

- Sahip olduğu form, renk ve konstrüksiyon olarak her türlü mimari projeye uygulanabilir özellikleri ile gerek pencere sektörünün gelişiminde gerekse sektörel rekabet üstünlüğ̈nün sağlanmasında akıllı ahşap teknolojilerine yönelik pencere sistemi tasarımlarına yönelmenin önemi ortaya çıkmıştır. 


\section{Kaynaklar}

AG Holzmann, (2009), Ahşap Kompozit Pencereleri, Yapı Tanıtım Bülteni, 160, 01 Eylül 2009, İstanbul.

Anonim, (2005), Wood products and panels, EUWID No.30, July 27, 2005, Vol.79; EUWID No.42, October19, 2005, Vol.79, Germany.

Anonim, (1998), HK Holz- und Kunstst off verarbeitung, 6/1998, s.26-28, Germany.

Dilik, T., (1999), Lamine ağaç malzemeden pencere profili üretimi ve bazı kalite özelliklerinin belirlenmesi, İ.Ü. Orman Fakültesi Dergisi, 49 (1999), 59-82, İstanbul.

Dilik, T.,Altun, B., (2007), Studies on some properties of quality and performance in wood windows, American Journal of Applied Sciences 4 (3) 112-121, New York.

Dilik, T., Kurtoğlu, A., (1998), Türkiye doğrama endüstrisi ve ahşap pencere üretiminde ilke ve yaklaşımlar, Cumhuriyetimizin 75. Yılında Ormancılığımız Sempozyumu Bildiri Kitabı, 21-23 Ekim 1998, İstanbul, İ.Ü. Yayın No: 4187 Orman Fakültesi Yayın No: 458, 584-593.

Dilik, T., Kuşçuoğlu, Ö., (2008), Studies of problems and developments of industrial wood windows production in Turkey, International Symposium, Bottlenecks, Solutions, and Priorities in the Context of Functions of Forest Resources, Proceedings of Oral Presentations, ISBN 978-975-9060-44-2, pp.91-102, 17-19 October 2007, Istanbul University, Faculty of Forestry, Istanbul, Turkey.

Dilik, T.,Kurtoğlu, A., Kuşçuoğlu, M., Ö., (2009), Teknolojik yenilikler çerçevesinde pencere üretimindeki gelişmeler, I. Ulusal Batı Karadeniz Ormancılık Kongresi Bildiriler Kitabı, pp.676-682, Bartın.

Dilik, T., ve Kurtoğlu A., (2019), Doğrama Endüstrisi Ders Notu (Basılmamıştır), İ.Ü.Cerrahpaşa Orman Fakültesi, Orman Endüstri Mühendisliği Bölümü, İstanbul.

Işık, B., (1994), Ahşap doğramada hasar, Yapı Dergisi,152, Temmuz 1994, s.67, İstanbul.

Sakarya, S. (2003), Ahşap kapı ve pencere sektörü değerlendirme raporu, Orta Anadolu İhracatçı Birlikleri Yayınları, Ankara.

TS EN 1026, (2002), Kapı ve pencereler-hava geçirgenliği deney metodu, Türk Standartları Enstitüsü Yayınları, Ankara.

TS EN 1027, (2003), Pencereler-deney metotları-statik basınç altında su geçirmezlik deneyi, Türk Standartları Enstitüsü Yayınları, Ankara.

URL 1, (2020), AG Holzmann Photos, http://www.agholzmann.com.tr/agacpencere/, Son erişim tarihi: 04.06.2020.

URL 2, (2020), Firatpen, http://www.firatpen.com.tr/cmsfiles/documents/firatpentr.pdf? $\mathrm{v}=30$, Son erişim tarihi: 04.06.2020.

URL 3, (2020),Pimapen, https://www.pimapen.com.tr/kurumsal/misyon-ve-vizyon, Son erişim tarihi: 04.06.2020.

URL 4, (2020), Rehau, https://www.rehau.com/tr-tr/pencereler-ve-kapilar, Son erişim tarihi: 04.06.2020. 